This document is the accepted manuscript version of the following article:

Arraigada, M., Bueno, M., \& Part1, M. N. (2020). Downscaled

accelerated trafficking of novel asphalt joints based on the induction

heating technology. In A. Chabot, P. Hornych, J. Harvey, \& L. G.

Loria-Salazar (Eds.), Lectures notes in civil engineering: Vol. 96.

Accelerated pavement testing to transport infrastructure innovation.

Proeedings of 6th APT conference (pp. 291-299).

https : //doi .org/10.1007/978-3-030-55236-7_30

\title{
Downscaled accelerated trafficking of novel asphalt joints based on the induction heating technology
}

\author{
M. Arraigada*, M. Bueno and M. N. Partl \\ Empa, Swiss Federal Laboratories for Material Science and Technology, \\ Road Engineering/Sealing Components, Ueberlandstr. 129, CH-8600 Duebendorf, \\ Switzerland \\ martin.arraigada@empa.ch
}

\begin{abstract}
Longitudinal joints are discontinuities in the asphalt pavement structures, often missing good interlock between the aggregates, strong binder adhesion and sufficient treatment of the joint during construction with bonding agents. Furthermore, the density of the asphalt near the joint is generally lower than in the rest of the pavement. Therefore, joints are usually the weakest location in the structure and the effect of traffic loading and environment can cause premature failure at these locations. This study evaluates the durability of a novel type of joints constructed with induction heating using asphalt concrete with metallic additives. Previous laboratory tests suggest that these types of joints could outperform traditional construction methods. Four slabs with artificial longitudinal joints were prepared in the laboratory and loaded until failure with the downscaled model mobile load simulator MMLS3. In two of these slabs, the joints were built without any treatment and with a self-adhesive tape, accounting for standard joint construction procedures. In the other two slabs, metallic additives were locally added to the asphalt mixture close to the each joint and induction heating was used for improving the interlock and bond between the neighboring sides. For trafficking, the MMLS3 was placed on the slabs, such that footprint of the tires was just beside each joint. A comparative analysis of the fatigue performance of the different slabs shows that the novel designs could last two to six times longer than traditional joints.
\end{abstract}

Keywords asphalt joints; downscaled accelerated trafficking, MMLS3, induction heating 


\section{Introduction}

Asphalt joints are formed when two adjacent asphalt road layers are compacted at different times. One of the most common types is the longitudinal joint in a multiple lane road. When the first lane is compacted, the edges have usually no lateral confinement and therefore lower density than in the center of the lane (Korzilius 2018). When constructing the adjacent layer later in time, the first layer is already at ambient temperature. In many cases, bonding of old and new binder is challenging and the interlock between the granular skeleton of both layers is poor. For all these reasons, joints are usually the weakest locations in a pavement and represent a discontinuity in the layer's structure with limited capacity of transferring traffic loads within the pavement. The effect of traffic loads and environment, like moisture or temperature fluctuations, negatively influence the performance of joints causing premature failure of the road at these locations. Deteriorated joints may trigger fast loss of functionality of pavements causing serious safety problems, reduction of driving comfort and increase of traffic noise. One of the causes for the deterioration of longitudinal joints is the difference in density on either side of the joint. This is also related with the regime of the roller compaction and the geometry of the contact surfaces within the joints. Several technical notes and recommendations propose constructive measures like edge cutting or special compaction strategies (Buncher 2012, Kandhal and Mallick 1997). Furthermore, joint tapes as well as bituminous coatings for improving the bond between both sides of the joints are commercially available. However, these technologies present problems, such as hindering transverse drainage of water through longitudinal joints in porous asphalt (Wang and Oeser 2015). In addition, technologies such as joint tapes, focus only on adding waterproofness to the pavement structure but not on load transfer capabilities.

The use of a magnetic field energy for inductively heating up asphalt concrete modified with metallic additives is a technology that has been studied during the last decade (Garcia et al. 2011, Jeoffroy et al. 2016). Several scientific papers showed that this technology is able to heal micro-cracks in asphalt concrete not only at laboratory but also at test section scale (Liu et al. 2013) and with full-scale accelerated pavement testing experiments like in the german duraBAST (Xu et al. 2018).

Considering the previously described problems, induction heating seems to be a suitable technology for improving the durability of joints by healing the already existing discontinuities in the asphalt concrete as if they were micro-cracks produced, for example, by fatigue loads. Therefore, this technology offers a maintenance option for in-situ for healing of asphalt pavements including micro-debonded joints. In fact, it has been experimentally shown that micro-cracks generated by repeated traffic loads and thermal stresses at low temperature can be closed before they grow and propagate into the road structure (Garcia et al. 2013). In this way, it is possible to improve the cohesive and adhesive bonds in asphalt before total failure occurs, thus extending pavement's life span. Within the frame of a research project dealing with the use of heating technology for producing more durable asphalt 
joints, the authors of this paper issued two publications where the idea was evaluated using laboratory specimens for performing adhesion tests, four point bending experiments, stiffness modulus evaluations and resistance to fracture (Bueno et al. 2017, Bueno et al. 2018). This paper presents the results of downscaled accelerated pavement testing with the model mobile traffic load simulator MMLS3 on slabs with artificial joints in order to validate the results obtained at laboratory scale. The objective of these tests was to compare fatigue performance of traditionally constructed joints with innovative ones modified with metallic additives for applying induction heating technology.

\section{Experimental plan}

In the experimental setup, slabs with artificial longitudinal joints in the center, were loaded with the MMLS3. The machine was positioned such that wheel path of the rolling tires was always one the same side of the joint. Tests were performed on two slabs with standard joints and two slabs with joints produced using the induction heating technology. MMLS3 loading was applied until a visible crack from the bottom to the surface appeared, as explained in the following sections.

\subsection{Induction Heating Setup}

The working principle of the induction heating process for pavements is based on the application of an electromagnetic field generated with an inductor coil. If an asphalt mixture is modified with electrically conductive particles, the electromagnetic radiation will increase their temperature due to the Joule effect. A more detailed explanation about the working principle on asphalt healing can be found elsewhere (Jeoffroy et al. 2016). In this work, the induction heating experiments were performed with a test coil of $20 \mathrm{~cm}$ and a $20 \mathrm{~kW}$ generator with a maximum frequency of $80 \mathrm{kHz}$. A special mobile induction coil was designed and constructed, such that it was possible to use the roller compactor and the coil at the same time.

\subsection{Materials and Manufacture of Slabs}

In order to obtain realistic joints at lab scale, $1.80 \mathrm{~m}$ long and $0.60 \mathrm{~m}$ wide slabs were built at lab scale by reproducing a process with similar compression and tension strain fields as during pavement construction. A steel roller vibratory compactor was used to compact the slab in two stages to form a joint. An asphalt concrete mixture (AC 11) with a maximal nominal aggregate size of $11 \mathrm{~mm}$ and $5.4 \%$ 
wt. bitumen 50/70 was compacted until reaching a thickness of $4 \mathrm{~cm}$ and $4.5 \%$ air void content by controlling different experimental parameters such as the number of rolling passes. The surface temperature of the slabs during compaction was monitored using a full color infrared camera. In order to simulate a longitudinal joint, a defined amount of asphalt mixture was compacted as first lane (Figure 1). Once the material had cooled down to room temperature, the same amount of mixture was laid alongside and compacted as second lane, taking care that both lanes have the same width and the joint is approximately in the center of the slab.

Four slabs, each with a different type of joint, were prepared for testing with the MMLS3. For the slab S1, the first lane of the slab was allowed to cool down to room temperature before the asphalt mixture for the second lane was laid and compacted at about $130{ }^{\circ} \mathrm{C}$. In this case, no confinement was provided during the compaction of the first lane, thus producing an edge of irregular shape with an angle of approximately $60^{\circ}$ following the friction angle of the hot asphalt material. In the case of slab S2, the compaction of the first lane was carried out as previously explained, but the free edge was saw cut vertically along the centerline of the slab. In this case, extra mixture was used in the construction of the first lane in order to account for the waste cut material (Figure 2). Then, a self-adhesive tape (TOK-Band SK $\AA, 1$ $\mathrm{cm}$ thickness) was attached to the cut edge before the second lane was laid and compacted. In both cases, S1 and S2, the joints represent standard procedures and der served as control slabs.
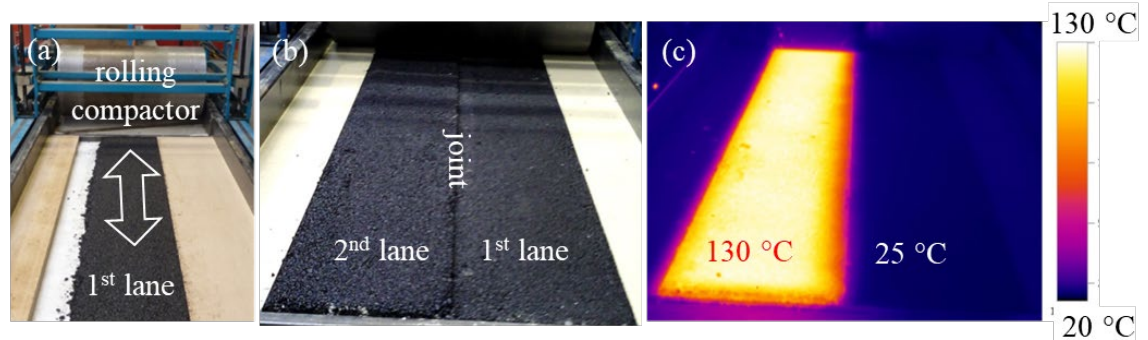

Fig. 1 pictures of slab S1 construction process: a) view of the compaction of the first lane, b) compaction of the second lane and c) infrared image of the compaction of the second lane
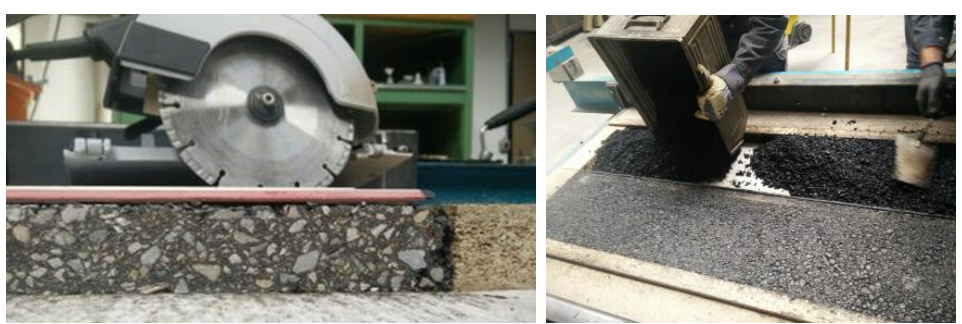

Fig. 2 saw cut of slab S2 free edge and construction of the second lane with the use of a selfadhesive tape 
In addition, two slabs, I1 and I2, were build using the induction-heating machine. In this case, $14 \%$ wt cast iron particles $(0.6 \mathrm{~mm}$ to $1.0 \mathrm{~mm})$ were added as metallic additives to the AC11 mixture around the joint (15 cm to each side). The construction procedure for the slab I1 was similar than in case S1. However, the area close to the joint was heated with the mobile induction coil up to a surface temperature of ca. $130^{\circ} \mathrm{C}$ and post-compacted again with the roller compactor (Figure 3 ). In the case of Slab I2, the free edge of the first lane was heated with the induction coil before laying and compacting the second lane. This procedure compared to the usual way of attaching infrared heaters to finishers. (Daniels 2006). Table 1 summarizes the characteristics of the slabs for MMLS3 testing.

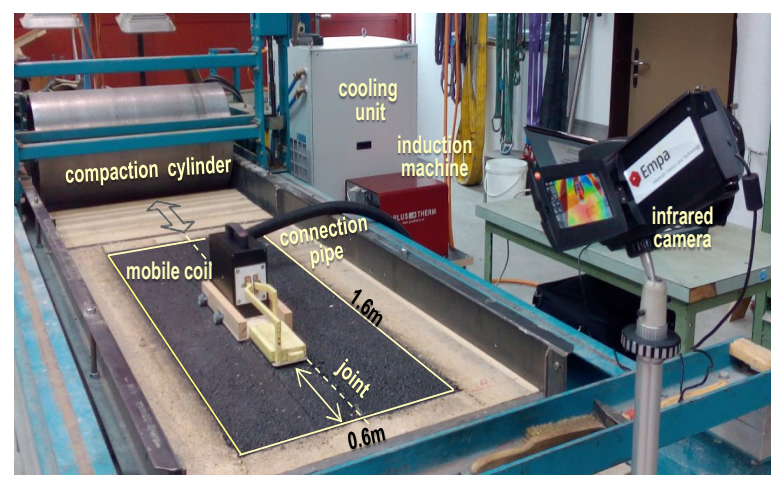

Fig. 3 induction heating of the joint and post-compaction for slab I1

Table 1 types of joints studied in this work

\begin{tabular}{|c|c|c|c|}
\hline $\begin{array}{l}\text { slab's } \\
\text { name }\end{array}$ & material & type of joint & remarks \\
\hline S1 & $\mathrm{AC} 11$ & hot - cold & $\begin{array}{r}\text { no confinement of first lane's edge, no } \\
\text { cut, no treatment }\end{array}$ \\
\hline $\mathrm{S} 2$ & $\mathrm{AC} 11$ & hot - cold & $\begin{array}{r}\text { cut and self-adhesive tape (TOK-Band } \\
\text { SK } ®)\end{array}$ \\
\hline I1 & $\begin{array}{r}\text { AC11 } \\
+14 \% \text { metal }\end{array}$ & hot - cold + postcompaction & $\begin{array}{r}\text { after construction, induction heating and } \\
\text { extra post-compaction }\end{array}$ \\
\hline $\mathrm{I} 2$ & $\begin{array}{r}\mathrm{AC} 11 \\
+14 \% \text { metal }\end{array}$ & hot - warm & $\begin{array}{l}\text { before the construction of } 2^{\text {nd }} \text { lane, induc- } \\
\text { tion heating on the } 1^{\text {st }} \text { lane and afterwards } \\
\text { compaction of both lanes }\end{array}$ \\
\hline
\end{tabular}




\subsection{MMLS3 Testing Setup}

The load simulator MMLS3 is a downscaled traffic load simulator for loading real pavements or model pavements with rolling pneumatic tires. It can apply up to 7200 load cycles per hour, which represents a loading frequency of $2 \mathrm{~Hz}$. Each tire has a diameter of is $30 \mathrm{~cm}$ and a load of $2.1 \mathrm{kN}$ with an inflation pressure of $800 \mathrm{bar}$. The loading length of the device is $1 \mathrm{~m}$. A complete description of this accelerated pavement device can be found elsewhere (Bueno 2016).

The resistance of the joints to fatigue cracking and their capability of transferring the load between both sides of the joints was evaluated by placing the MMLS3 such that the footprint of the tires was just beside the joint. This means that the load was not applied symmetrically to the slab geometry as shown in Figure 4.

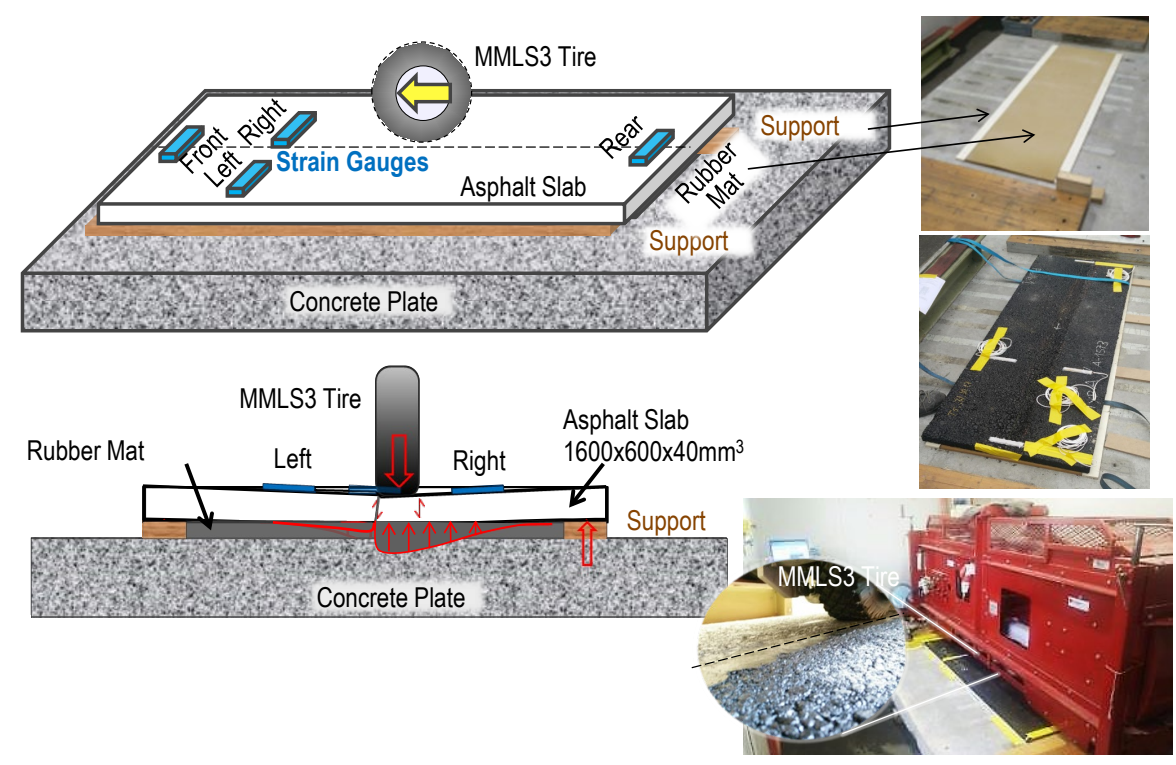

Fig. 4 schematic view of the MMLS3 testing setup

In order to simulate the bending of a pavement layer under load, the long edges of the slabs were laid onto wooden supports. Between the profiles and below the slab, a thin rubber mat was placed as soft elastic foundation, simulating the subgrade. Everything was standing on top of a rigid concrete plate where the MMLS3 was attached. The deformation of the slabs under loading of the rolling tires was measured periodically using four strain gauges. Two strain gauges were glued on the surface, perpendicular to the joint at the rear and front edges of the slab (rear and front strain gauges). The other two strain gauges were glued on the surface at the right and left side of the wheel path. Because of initiation and progression of micro and visible cracks, the stiffness of the slabs (considered as simple supported 
plates on elastic foundation) was expected to decrease, leading to an increase in bending deformation under load that is measured indirectly with the strain gauges. The loading was carried out in a container at $20^{\circ} \mathrm{C}$. Considering that the temperature and the loading speed are maintained constant, any change in the amplitude of the deformations can be attributed to a crack-induced change in stiffness of the slabs. These measurements together with visual inspections were the input for the following comparative analysis of the fatigue performance of the different joints.

\subsection{Data Analysis}

Figure 5 presents the measurements of all strain gauges in a 1s time window at the beginning of the loading with the MMLS3. In this timeframe, it is possible to see two loading cycles, i.e. the complete passing of two tires over the loading path of $1 \mathrm{~m}$. During $0.1 \mathrm{~s}$, two tires are in touch with the slab: one is arriving and the other one is leaving the slab. When a tire touches the slab surface, there is a compression pulse in the rear strain gauge, which goes back to zero when the same tire leaves the slab. In the same time frame, the compression measured at the front strain gauge increases and reaches the maximum when both tires are in contact with the slab. On the other hand, right and left stain gauges show tension peaks when the tires are passing close to them.

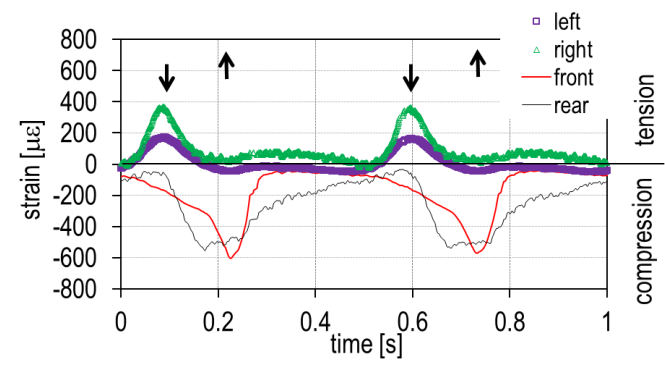

Fig. 5 strain gauge measurements over a time widow of $1 \mathrm{~s}$

As previously explained, it is expected that if the slab presents cracks due to fatigue, the bending stiffness of the system will change. This in turn, will have an effect on the measured strains. Therefore, a change in the difference between the maximum and minimum measured values for each loading cycles (called strain amplitude) is an indication of a cracked slab. 


\section{Results}

Figure 6 shows the strain amplitudes for all four slabs: It can be observed that the strain amplitudes of the rear and front strain gauges increase until reaching a maximum. From that point, a decrease in the strain amplitudes occurs. Coincidently with the maximum of the measured strain amplitudes, visual inspections showed in all cases a longitudinal crack at the joint location (see the right picture of Figure 6). In this way, the slabs with standard joint types (S1 and S2) broke after ca. 8,000 and 10,000 MMLS3 load passings, whereas the joints manufactured with induction heating lasted longer, failing after ca 16,000 and 65,000 load passings in case of slab I2 and I1 respectively.
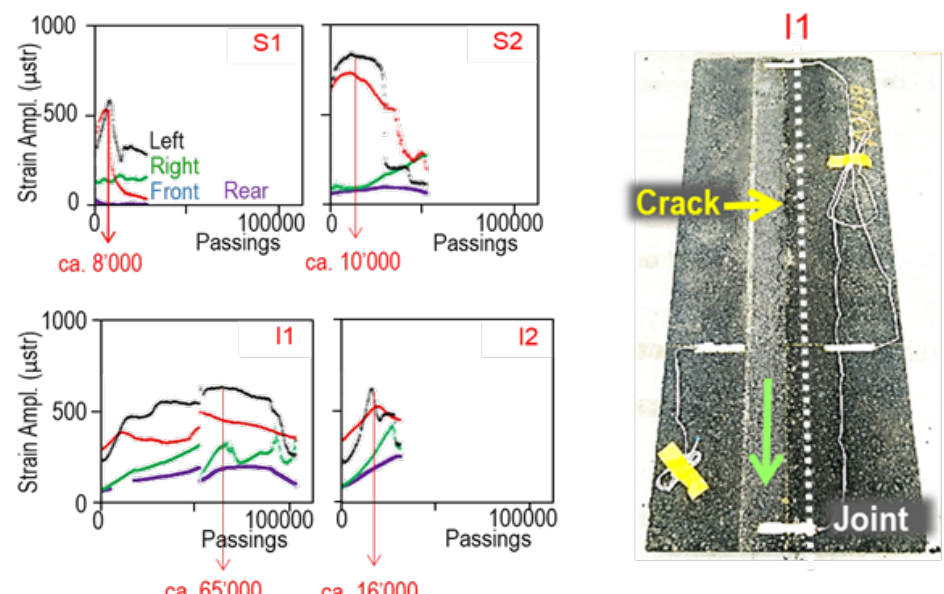

Fig. 6 deformation amplitudes of each of the slabs and strain gauges and view of slab I1 after reaching the fatigue limit

These results, summarized in Table 2, show that the new type of joints under the accelerated loading of the MMLS3 outperformed the standard construction. This confirms the results obtained with specimens at laboratory size level and already published in (Bueno et al. 2017, Bueno et al. 2018)

Table 2 types of joints studied in this work

\begin{tabular}{rr}
\hline slab's name & No. MMLS3 loads passings until damage \\
\hline S1 & 8,000 \\
S2 & 10,000 \\
I1 & 65,000 \\
I2 & 16,000 \\
\hline
\end{tabular}




\section{Conclusions}

In this work, the evaluation of the induction heating technology for improving longitudinal joints in asphalt concrete pavements was evaluated through downscaled accelerated pavement trafficking. To this end, two slabs with standard joints and two slabs with joints constructed using induction were prepared with a roller compactor. The slabs were loaded with the model mobile load simulator MMLS3 until fatigue failure. The performance was monitored through visual inspections and the use of strain gauges.

Results showed that an extra post-compaction after locally heating the area of the joint with an induction coil, improved the performance by almost six times as compared to commercial treatments. Heating the cold edge with the induction coil before laying the second lane resulted in a better performance as well, but in this case only by not more than two times. These findings can be used as a proof of concept of the method and as a preliminary step to create prototypes for a future full-scale implementation.

\section{References}

Bueno, M., Arraigada, M., Partl, M.N. (2016) Damage detection and artificial healing of asphalt concrete after trafficking with a load simulator, Mechanics of Time Dependent Materials, 20, $265-279$

Bueno M, Arraigada M, Partl MN (2017) Improvement of longitudinal asphalt joints performance by using induction heating (p. (13 pp.)) Presented at the ISAP 4th international symposium on asphalt pavements and environment. Tokyo, Japan.

Bueno M, Arraigada M, Partl MN (2018) Induction heating technology for improving compaction of asphalt joints, International Journal of Pavement Engineering, doi: $10.1080 / 10298436.2018 .1554218$

Buncher M (2012). The best way to roll a joint and everything else you should know about constructing longitudinal joints; The Ontario Hot Mix Producer's Association magazine, Asphaltopics Spring 2012

Daniels JS (2006) Use of an infrared joint heater to improve longitudinal joint performance in hot mix asphalt pavements perform. Constr. Facil., 2006, 20(2): 167-175

García A, Schlangen E, van de Ven M, van Vliet D (2011) Induction heating of mastic containing conductive fibers and fillers. Materials and Structures, 44:499-508 DOI 10.1617/s11527-010$9644-2$

Garcia A, Bueno, M., Norambuena-Contreras, J., Partl, M.N. (2013) Induction Healing of Dense Asphalt Concrete. Construction and Building Materials, 49, 1-7 
Jeoffroy E, Koulialias D, Yoon S, Partl MN, Studart AR (2016) Iron oxide nanoparticles for magnetically-triggered healing of bituminous materials. Construction and Building Materials 112, 497-505, http://dx.doi.org/10.1016/j.conbuildmat.2016.02.159

Kandhal P, Mallick R (1997) Longitudinal Joint Construction Techniques for Asphalt Pavements, NCAT Report 97-4

Korzilius J (2018) Longitudinal Joint Construction, NRRA State of Practice

Liu Q, Schlangen E, van Bochove G (2013) The first engineered self-healing asphalt road; how is it performing? ICSHM2013, p 484-488

NCAT National Center for Asphalt Technology (2006) Transportation Research Circular E-C105: Factors Affecting Compaction of Asphalt Pavements

Wang D, Oeser M (2015) Interface treatment of longitudinal joints for porous asphalt pavement. International Journal of Pavement Engineering 17 (8), p741-752

Xu S, García A, Su J, Liu Q, Tabaković A, Schlangen E (2018) Self-Healing Asphalt Review: From Idea to Practice. Advanced Materials Interfaces, 5(17), 1-21. [1800536]. https://doi.org/10.1002/admi.201800536 